\title{
Reply to Discussion of "Modulus Ratio and Joint factor Concepts to Predict Rock Mass Response" by T. Ramamurthy, G. Madhavi Latha, T.G. Sitharam, Rock Mech Rock Eng, 2017. 50:353-366. doi:10.1007/s00603-016-1112-z
}

\author{
G. Madhavi Latha ${ }^{1}$
}

Published online: 8 May 2017

(c) Springer-Verlag Wien 2017

We thank the discusser for appreciating our work and highlighting his complementary work on joint factor. The discusser raised three important issues in the discussion: influence of infill material on the joint strength parameter used for the calculation of joint factor; relating the joint factor to the RQD, GSI, RMR or Q; and estimation of strength and modulus using joint factor. Our detailed response to these three points is as follows.

The joint factor is a combination of joint frequency, joint inclination parameter that depends on the orientation of the critical joint and strength along the joint considered. For calculating joint strength parameter for joints filled with a gouge material and reached the residual shear stage, Ramamurthy (1993) has provided a table, which gives the least strength parameter of 0.18 for joints filled with claysilt (75\% clay) and maximum strength parameter of 1.0 for joints filled with gravelly sand.

While calculating the joint strength parameter, only the relevant strength in terms of friction $\left(\phi_{j}\right)$ has to be considered. Because of cementation, the cohesion component has to be converted into an equivalent friction and used. For calculating the strength parameter for clean joints, joint strength parameter is correlated to the uniaxial compressive strength of the intact rock. Clear guidelines are also given for the estimation of other two parameters, namely joint frequency and joint inclination.

The joint factor should not be linked to GSI, RQD, RMR or Q classifications. RQD does not consider two of the parameters considered in joint factor calculation, joint inclination and joint strength. The third parameter joint frequency is a realistic parameter, and there is no ambiguity in its use.

In the laboratory tests, even a small kink or step considerably influences both strength and modulus. Therefore, upper and lower bound limits were given to the strength and modulus estimations based on joint factor (Ramamurthy 2001). So a near-lower-bound value of strength and modulus from these correlations should be adopted for a known value of $J_{f}$. These solutions were validated against large experimental data of rocks and rock-like materials and were successfully applied to a number of problems, like large underground cavities, tunnels and deep mines. Introduction of empirical multiplication factors to $J_{f}$ so as to get strength and modulus of rock mass may not help in predicting responses of in situ problems.

We certainly appreciate the effort and views of the discusser on our paper.

\section{References}

Ramamurthy T (1993) Strength and modulus responses of anisotropic rocks. In: Hudson JA (ed) Comprehensive Rock Engineering. Chapter 13. Pergamon Press, Oxford, pp 313-329

Ramamurthy T (2001) Shear strength responses of some geological materials in triaxial compression. Int J Rock Mech Min Sci 38:683-697

G. Madhavi Latha

madhavi@civil.iisc.ernet.in

1 Bangalore, India 